\title{
Comparison of Intervention Strategies for Control of Triatoma dimidiata in Nicaragua
}

\author{
F Acevedo, E Godoy*, CJ Schofield**/+ \\ Ministerio de Salud, Apartado 2900, Managua, Nicaragua *Bayer SA, Apartado 1573, Guatemala City 01901, \\ Guatemala **LSHTM, London WC1 E7HT, UK
}

The effectiveness of three operational strategies for the control of Triatoma dimidiata was compared by a field trial in the Department of Madriz, Nicaragua. One strategy involved full pretrial evaluation, followed by spraying of all houses irrespective of whether or not they had been found to be infested. The second strategy minimised the pretrial evaluation by considering the locality infested as soon as one house was found to be positive, followed by spraying all houses. The third strategy involved full pretrial evaluation, followed by spraying only those houses found to be positive. Evaluation after twelve months indicated that all three strategies were similarly effective, since all sprayed houses remained free of infestation. However, comparative estimates of the unit intervention costs indicated that strategies 1 and 2 were substantially less efficient than the third strategy of spraying only positive houses.

Key words: Chagas disease - Triatoma dimidiata - vector control - Nicaragua

Triatoma dimidiata Latreille (Hemiptera, Reduviidae, Triatominae) is the most widespread vector of Chagas disease in Central America. Its distribution ranges from southern Mexico through all countries of Central America into parts of Colombia, Ecuador, Venezuela and northern Peru (Lent \& Wygodzinsky 1979, Schofield 1994). In Nicaragua it has been recorded from all Departments except in the northeast of the country which has not yet been surveyed for Chagas disease vectors (MINSA, Managua, unpublished survey report 1999).

Following the launch of the Central American Initiative against Chagas Disease in 1997 (WHO 1998) the Ministry of Health of Nicaragua (MINSA) has been carrying out surveys for Chagas disease vectors and implementing control trials. The first priority is the elimination of Rhodnius prolixus, which seems to be the most efficient vector of Chagas disease in Central America (Ponce et al. 1995, Paz Bailey 1998) and is considered a feasible candidate for complete eradication from the region since it seems to be exclusively domestic in Central America (Schofield \& Dujardin 1997, Dujardin et al. 1998). In Nicaragua, our surveys during 1998-1999 indicate that $R$. prolixus is now confined to a few localities along the border with

\footnotetext{
${ }^{+}$Corresponding author. Fax: +44-171-636.8739. E-mail: C.J.Schofield@1shtm.ac.uk Received 14 December 1999 Accepted 3 July 2000
}

Honduras, whereas $T$. dimidiata is much more widespread. Moreover, T. dimidiata is known to have extensive silvatic ecotopes (Zeledón 1981) and cannot be considered a feasible candidate for complete eradication. We are therefore concerned to develop the most efficient strategy for its long term control.

As shown by studies in Brazil (eg. Oliveira Filho 1989), the cost of house spraying against domestic vectors of Chagas disease depends heavily on the cost of salaries, per diems and transport for the field teams, as well as the cost of insecticide. For this reason, the most efficient operational strategy would minimise the number of visits made to each house and each locality in the endemic areas. In this paper, we report the results of a control trial which was designed to compare three different operational strategies for the control of $T$. dimidiata.

\section{MATERIALS AND METHODS}

The trial area included parts of the municipalities of Uniles, El Chinchal, El Porcal, San Sebastiano, and Santa Isabel, in the Department of Madriz, close to the border with Honduras. The trial protocol was designed to compare three types of operational strategy as follows: (1) Full pretrial evaluation, followed by treatment of all houses. All houses were first checked for the presence of bugs. Then all houses were sprayed, even if they appeared to be negative on the first survey; (2) Minimum pretrial evaluation, followed by treatment of all houses. The locality was checked, and as soon as one bug was found the whole locality was considered suspect and all houses were sprayed; (3) Full 
pretrial evaluation, followed by treatment of positive houses only. All houses were first checked, but only those houses where bugs were found were treated.

The pretrial evaluations and subsequent spraying were carried out in August-September 1998 by teams from the ETV section of the local health service (SILAIS) of the Departmental capital, Somoto. These field teams were well experienced in vector control activities against mosquitoes, but had little previous experience with Triatominae. Team supervisers had life-size colour photographs of all stages of $T$. dimidiata and $R$. prolixus to show to householders, and each member of the field team was equipped with torch and forceps in order to search the designated houses for 15 min during the pretrial evaluations. To 'back correct' the survey results, all householders were also given a plastic bag during the spray round, and asked to collect any bugs (and other insects) that they could collect during the $24 \mathrm{~h}$ after spraying. These bags were then collected and replaced with new bags. The resulting back correction showed that at least one house negative on the pretrial evaluation was in fact infested.

Designated houses were sprayed with cyfluthrin 10WP (SOLFAC®) at a target dose rate of $50 \mathrm{mg}$ a.i./ $/ \mathrm{m}^{2}$ using 81 Hudson $\mathrm{X}$-pert spraypacks. All internal wall and roof surfaces were sprayed, together with peridomestic dependencies such as chicken coops and latrines. A total of 70 houses was sprayed, as follows:

The locality chosen for strategy 1 was Uniles $\left(13^{\circ} 26 \mathrm{~N}, 86^{\circ} 37 \mathrm{~W}\right)$ with 50 houses, of which 49 could be visited in the pre and postspray evaluation. Thirty eight houses were sprayed, of which six had been found to be positive by prespray evaluation, compared to seven $(18.4 \%)$ by the postspray correction from the plastic bag collections. Spraying was completed by five men in approximately $7 \mathrm{~h}$, using 34 charges of Solfac 10WP.

The locality chosen for strategy 2 was El Chinchal $\left(13^{\circ} 30 \mathrm{~N}, 86^{\circ} 33 \mathrm{~W}\right)$ with a total of 29 houses. This locality was originally selected on the basis of discussion with local field staff, who reported that it was a locality previously infested with $R$. prolixus. However, the first house checked was found to be infested with $T$. dimidiata, and the local people recognised only the photos of $T$. dimidiata and not those of $R$. prolixus. In line with strategy 2 therefore, 26 houses were sprayed. Only one of these had been checked (and found positive) before spraying, but the postspray check of the plastic bags showed that nine $(34.6 \%)$ were in fact positive (all $T$. dimidiata). Spraying was completed by four men in approximately $5 \mathrm{~h}$, using 30 charges of Solfac 10WP.
The localities chosen for strategy 3 were El Porcal, Santa Isabel, and San Sebastiano, with a total of 182 houses. During the prespray evaluation of 110 of these houses, two houses in each of these localities had been found infested with $T$. dimidiata, and only these six houses were sprayed. Spraying was completed by three men in approximately $5 \mathrm{~h}$, using eight charges of Solfac 10WP.

Twelve months after spraying, in September 1999, all houses in the above localities were resurveyed for the presence of $T$. dimidiata (49 houses in Uniles, 29 houses in El Chinchal, and 182 houses in the other three localities). This evaluation was carried out by the same teams involved in the original spraying, but the teams were additionally equipped with dislodgant sprays of $0.2 \%$ tetramethrin (see Pinchin et al. 1980) to assist in searching for bugs.

\section{RESULTS}

Householders were generally pleased by the spraying. Almost all recognised photographs of $T$. dimidiata (but not of $R$. prolixus) although their main complaints about domestic pests were, in order of importance: bedbugs, fleas, cockroaches, scorpions, mosquitoes. All were satisfied with the applied product, with several noting that it did not smell nor leave any obvious deposit. Many were particularly pleased at the rapid action against cockroaches and scorpions that fell shortly after spraying [in Uniles and El Chinchal, the plastic bag collections after spraying showed that $81 \%$ of houses had cockroach infestations (Periplaneta americana) and $19 \%$ had scorpions].

For this trial a total of 70 houses was sprayed, of which 22 had been positive for $T$. dimidiata infestation (31.4\%). At the 12 month evaluation, bugs were not found in any of the sprayed houses, but one adult male and one fifth instar nymph of $T$. dimidiata were encountered in the chicken coop of one of the sprayed houses (1.4\%). By contrast, a total of 190 houses was not sprayed, of which ten were found to be infested at the 12 month evaluation $(5.3 \%)$. It is noteworthy that in each locality the infestation rates of houses that were surveyed but not sprayed remained very similar over the 12 month period (Figure).

To compare the relative costs of each intervention strategy we estimated the average cost of evaluation and treatment for each locality, assuming that the labour costs of evaluation and spraying were similar. Field personnel in Nicaragua at present receive a basic salary of $490 \mathrm{c}$ (US\$ 1 is approximately equal to 10 Cordobas) per month for 13 months per year, together with an additional $80 \mathrm{c}$ per month for active duties plus $162 \mathrm{c}$ per month if they have more than seven years service. Per diems are calculated 
as $12 \mathrm{c}$ per day for field work, plus $40 \mathrm{c}$ per day if they cannot return home at night. With additional payments for uniform and boots, we estimate the average daily wage to be about $100 \mathrm{c}$. In this trial, an average of one house was sprayed per man-hour, giving an average of eight houses per man-day equivalent to $12.5 \mathrm{c}$ per house, which we take as the labour cost per house evaluated or per house sprayed. We do not know the cost of the insecticide which was donated for this trial, but guide prices from the Southern Cone region would suggest an average of
US\$ 4 per house sprayed (OPS 1998) so we take an average insecticide cost per house of $40 \mathrm{c}$, so that the unit cost of spraying would be $52.5 \mathrm{c}$ excluding transport costs. Applying these costs (Table I) shows that strategies 1 and 2 give broadly similar unit intervention costs, whereas strategy 3 greatly reduces the unit costs of intervention. Moreover, this conclusion is maintained even if we assume a doubling of labour costs to $25 \mathrm{c}$ per house and a halving of the insecticide costs to $20 \mathrm{c}$ (making the total spray cost $20+25=45 \mathrm{c}$ ) (Table II). Note that in this trial,

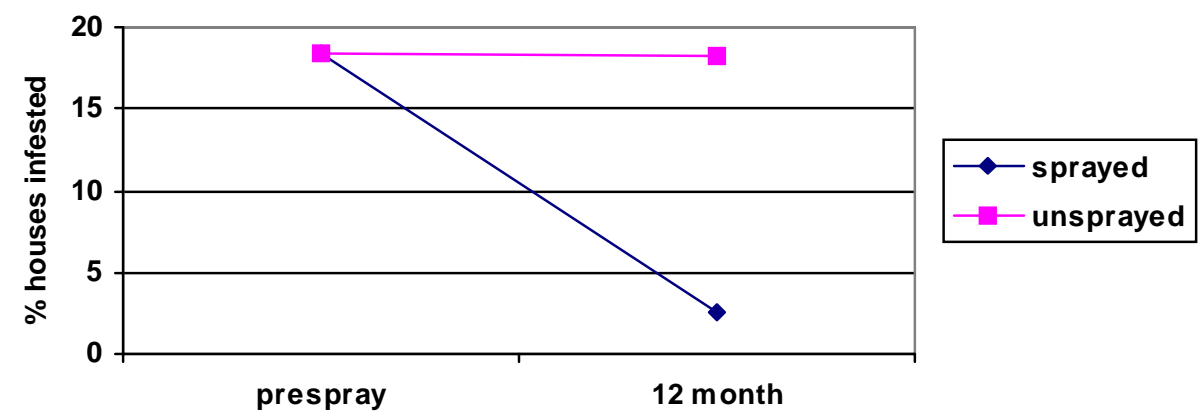

Strategy 1: full pretrial evaluation, followed by treatment of all houses.

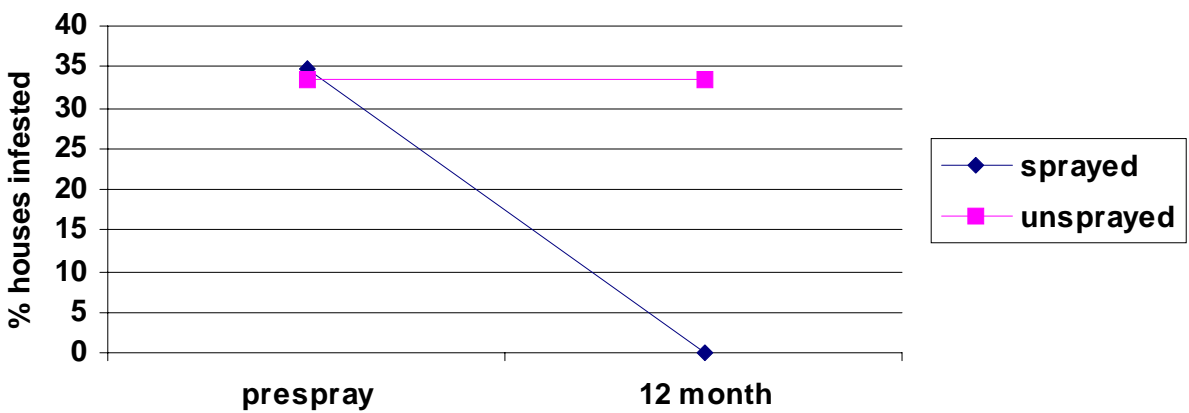

Strategy 2: minimum pretrial evaluation, followed by treatment of all houses.

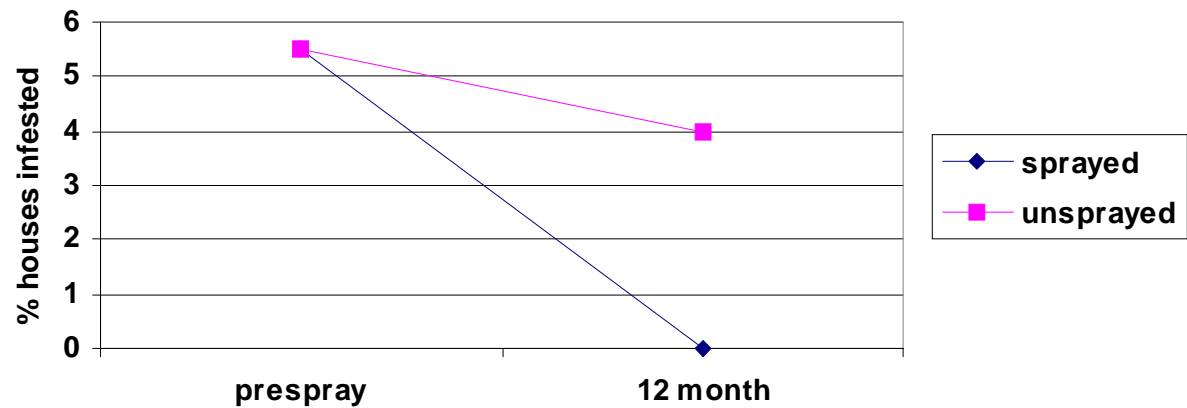

Strategy 3: full pretrial evaluation, followed by treatment of positive houses only.

Comparison of strategic options for the control of Triatoma dimidiata in Nicaragua. Strategy 1 (Uniles) involved 50 houses, of which 38 were evaluated and then sprayed. Forty nine were checked at the 12 month evaluation. Strategy 2 (El Chinchal) involved a total of 29 houses; only the first house was evaluated (and found to be positive) and then 26 houses in the locality were sprayed, leaving three houses unsprayed. All 29 houses were evaluated after 12 months. For strategy 3 (El Porcal, San Sebastiano, Santa Isabel) 110 houses were initially evaluated, of which six were found to be positive and were subsequently sprayed. After 12 months, 182 houses were evaluated from these localities. 
for strategy 2 the first house we evaluated was found to be infested, but it could have been the last. For Table II therefore, we have also assumed the median to be the average number of houses that would need to be searched following strategy 2 .

\section{DISCUSSION}

The results of this trial indicate that the three operational strategies have similar effectiveness, but substantial differences in unit intervention costs. T. dimidiata was effectively eliminated from all sprayed houses, reappearing at the twelve month evaluation only in one chicken house. However, strategies 1 and 2, which involved spraying all houses in a positive locality, both resulted in substantially higher relative costs compared to strategy 3 which involved spraying only those houses found to be infested. For large scale operations against $T$. dimidiata therefore, this would seem to be the most efficient intervention strategy, and has the additional advantage of minimising the amount of insecticide to be used.

The strategy of evaluating all houses and spraying only those found to be positive will always depend on the effectiveness of the initial evaluation, and in this trial it was found that the experience of the field teams is an important factor. At the outset, the teams had little experience in searching for domestic triatomine bugs, so that one house that seemed negative on the initial evaluation was shown to have been infested, by householder collections immediately after spraying. This points to the need for training of the field teams, and also the importance of satisfactory equipment (long blunt forceps and adequate torches for inspecting cracks, dislodgant sprays, and photographs of the bugs to show to the householders).

Because $T$. dimidiata seems to have extensive silvatic ecotopes throughout Central America (Zeledón 1981) it cannot be considered a feasible

\section{TABLE I}

Estimated unit intervention costs (Nicaraguan $\operatorname{Cordobas}^{a}$ ) for the three operational strategies, assuming an average labour cost for house evaluation of $12.5 \mathrm{c}$ and an average spray cost of $52.5 \mathrm{c}$

\begin{tabular}{|c|c|c|c|c|c|}
\hline & \multicolumn{2}{|c|}{ No. houses visited (A) } & \multirow{2}{*}{$\begin{array}{l}\text { Total cost of } \\
\text { evaluation } \\
\text { (B) }\end{array}$} & \multirow{2}{*}{$\begin{array}{l}\text { Total cost of } \\
\text { spraying } \\
\text { (C) }\end{array}$} & \multirow{2}{*}{$\begin{array}{c}\text { Cost per } \\
\text { house } \\
(\mathrm{B}+\mathrm{C}) / \mathrm{A}\end{array}$} \\
\hline & Evaluated & Sprayed & & & \\
\hline $\begin{array}{l}\text { Strategy } 1 \\
\text { Uniles }\end{array}$ & 38 & 38 & 475 & 1995 & 65 \\
\hline $\begin{array}{l}\text { Strategy } 2 \\
\text { El Chinchal }\end{array}$ & 1 & 26 & 12.5 & 1365 & 53 \\
\hline $\begin{array}{l}\text { Strategy } 3 \\
\text { El Porcal, San Sebastiano, } \\
\text { Santa Isabel }\end{array}$ & 110 & 6 & 1375 & 315 & 15 \\
\hline
\end{tabular}

$a$ : US\$ 1 is approximately equal to 10 Cordobas (C).

\section{TABLE II}

Estimated unit intervention costs (Nicaraguan Cordobas ${ }^{a}$ ) for the three operational strategies, assuming that the average labour cost for house evaluation has doubled to $25 \mathrm{c}$ and the average spray cost has halved to $25+20=45 \mathrm{c}$

\begin{tabular}{|c|c|c|c|c|c|}
\hline & \multicolumn{2}{|c|}{ No. houses visited (A) } & \multirow{2}{*}{$\begin{array}{l}\text { Total cost of } \\
\text { evaluation } \\
\text { (B) }\end{array}$} & \multirow{2}{*}{$\begin{array}{l}\text { Total cost of } \\
\text { spraying } \\
\text { (C) }\end{array}$} & \multirow{2}{*}{$\begin{array}{c}\text { Cost per } \\
\text { house } \\
(\mathrm{B}+\mathrm{C}) / \mathrm{A}\end{array}$} \\
\hline & Evaluated & Sprayed & & & \\
\hline $\begin{array}{l}\text { Strategy } 1 \\
\text { Uniles }\end{array}$ & 38 & 38 & 950 & 1710 & 70 \\
\hline $\begin{array}{l}\text { Strategy } 2 \\
\text { El Chinchal }\end{array}$ & $13^{b}$ & 26 & 325 & 1170 & 58 \\
\hline $\begin{array}{l}\text { Strategy } 3 \\
\text { El Porcal, San Sebastiano, } \\
\text { Santa Isabel }\end{array}$ & 110 & 6 & 2750 & 270 & 27 \\
\hline
\end{tabular}

$a$ : US\$ 1 is approximately equal to 10 Cordobas (C); $b$ : assuming that on average, half the houses would need to be searched to encounter the first infested house, rather than just the first house, as was the case in our actual trial. 
candidate for complete eradication from the region - unlike $R$. prolixus which seems to be an imported species that could be eradicated (Dujardin et al. 1998). For this reason, the intervention strategy against $T$. dimidiata must be sustainable over the long term, and will require an initial evaluation of houses in each locality, followed by spraying of positive houses and subsequent vigilance with repeat spraying wherever necessary. An additional factor favouring this approach is the relatively long generation time of $T$. dimidiata, which generally requires 6-12 months to complete its development cycle from egg to adult (Zeledón et al. 1970a, b). In addition, studies in Honduras (Ponce et al. 1995) and Guatemala (Paz Bailey 1998) have shown it to be a relatively inefficient vector compared to $R$. prolixus. These two factors allow time for the organisation of selective responses to reports of house infestations, provided that community-based vigilance can be maintained over a long period. Parallel experience in Brazil (eg. Dias 1987, Schofield \& Dias 1998) indicates that communitybased vigilance can be organised during the initial evaluations and spray interventions, such that householders report the finding of bugs to a local centre which can then organise respraying of the newly infested premises.

\section{ACKNOWLEDGEMENTS}

To Bayer SA for donation of the insecticide and technical support during this trial, which also benefitted from international collaboration through the ECLAT network. To the staff of SILAIS Somoto and the ETV teams, particularly Rolando Vasquez, Mario Antonio Alfaro, Santos Pablo Medina, Pedro Cárcamo Cruz, Roberto Bermudez, Francisca Artola Peña, Juan Rosalia Gonzalez, and Angelita Matute.

\section{REFERENCES}

Dias JCP 1987. Control of Chagas disease in Brazil. Parasitol Today 3: 336-341.

Dujardin JP, Muñoz M, Chavez T, Ponce C, Moreno J, Schofield CJ 1998. The origin of Rhodnius prolixus in Central America. Med Vet Entomol 12: 113-115.

Lent H, Wygodzinsky P 1979. Revision of the Triatominae (Hemiptera, Reduviidae), and their sig- nificance as vectors of Chagas disease. Bull Am Mus Nat Hist 163: 123-520.

Oliveira Filho AM 1989. Cost-effectiveness analysis in Chagas disease vector's control interventions. Mem Inst Oswaldo Cruz 84 (Suppl. IV): 409-417.

OPS 1998. VII Reunión de la Comisión Intergubernamental para la eliminación de Triatoma infestans y la interrupción de la transmisión de la tripanosomiasis americana por transfusión. Organización Panamericana de Salud, Washington DC, Document OPS/HPC/HCT/98.114, 78 pp.

Paz Pailey G 1998. Seroprevalence of Chagas Disease in Guatemala, MSc Thesis, LSHTM, London, 51 pp.

Pinchin R, Oliveira Filho AM, Pereira ACB 1980. The flushing-out activity of pyrethrum and synthetic pyrethroids on Panstrongylus megistus, a vector of Chagas disease. Trans R Soc Trop Med Hygiene 74: 801-803.

Ponce C, Ponce E, Avila MFG, Bustillo O 1995. Ensayos de intervención con nuevasherramientas para el control de la enfermedad de Chagas en Honduras. In Nuevas Estrategias para el Control Vectorial de la Enfermedad de Chagas en Honduras, Ministerio de Salud Publica, Tegucigalpa, p.10-16.

Schofield CJ 1994. Triatominae - Biologia y Control, Eurocommunica Publications, West Sussex, UK, 80 pp.

Schofield CJ, Dias JCP 1998. The Southern Cone initiative against Chagas disease. Adv Parasitol 42: 1-27.

Schofield CJ, Dujardin JP 1997. Chagas disease vector control in Central America. Parasitol Today 13: 141-144.

WHO 1998. Chagas disease: Central American initiative launched. TDR News 55: 6.

Zeledón R 1981. El Triatoma dimidiata (Latreille, 1811) y su Relación con la Enfermedad de Chagas, Editorial Universidad Estatal a Distancia, San José, Costa Rica, 146 pp.

Zeledón R, Guardia VM, Zuñiga A, Swartzwelder JC 1970a. Biology and ethology of Triatoma dimidiata (Latreille, 1811) I. Life cycle, amount of blood ingested, resistance to starvation, and size of adults. $J$ Med Entomol 7: 313-319.

Zeledón R, Guardia VM, Zuñiga A, Swartzwelder JC 1970b. Biology and ethology of Triatoma dimidiata (Latreille, 1811) II. Life span of adults and fecundity and fertility of females. J Med Entomol 7: 462469. 